\title{
Saccharin elation effect
}

\author{
JOHN P. J. PINEL and L. I. ROVNER \\ University of British Columbia, Vancouver, British Columbia, Canada
}

\begin{abstract}
Rats with continuous access to food and water increased their selection of a sodium saccharin solution following temporary withdrawal of the solution. In Experiment 1 this "saccharin elation effect" occurred at two different saccharin concentrations, but only when the subjects had continuous access to the saccharin solutions in the days before and after the withdrawal period. The more commonly used method of presenting the saccharin solutions for $1 \mathrm{~h}$ /day during the exposure periods produced negligible effects at both concentrations. In a second experiment, the magnitude of the saccharin elation effect was found to be a monotonically increasing function of the withdrawal period. Inconsistencies in the results of previous investigations of the saccharin elation effect seem to stem from the failure to use appropriate experimental parameters.
\end{abstract}

There have been several replications (cf. Ashton, Gandelman, \& Trowill, 1970; Dube, Ashton, \& Trowill, 1970) of the saccharin elation effect first reported by Gandelman and Trowill in 1969. Rats with continuous access to food and water were presented with a solution of sodium saccharin for $1 \mathrm{~h}$ /day until a stable baseline of consumption was established. Access to the sodium saccharin was then curtailed for several days, and, after the original schedule of sodium saccharin availability was reimplemented, selection of the saccharin solution was temporarily elevated above baseline levels.

\section{EXPERIMENT 1}

Pinel and Huang (1976) were the first to emphasize that this "elation effect" is not specific to solutions of sodium saccharin. A temporary increase in consumption has been demonstrated following the withdrawal and subsequent return of dilute solutions of three other substances: pure saccharin, quinine hydrochloride, and ethanol (Wayner, Greenberg, Tartaglione, Nolley, Fraley, \& Cott, 1972). In fact, the temporary elevation in ethanol selection following the interruption of access to weak ethanol solutions has itself been subjected to extensive investigation (cf. Sinclair, Walker, \& Jordan, 1973). This so-called alcohol deprivation effect and the saccharin elation effect have recently been subjected to a direct experimental comparison (Pinel \& Huang, 1976), and the similarity of the two effects suggested that they were likely manifestations of a single, underlying taste-related process. However, although the two effects seem to parallel each other almost exactly when studied under comparable conditions, they seem to differ in terms of their reliability. The interruption of access to weak ethanol solutions has invariably produced striking increases in alcohol selection (Sinclair, 1972); whereas, as Hoyenga and Hoyenga (1973) have

Donald Wilkie sponsors this paper and takes full editorial responsibility for it. previously pointed out, the effects of sodium saccharin withdrawal have been extremely variable. Our hypothesis was that this difference in reliability does not reflect a basic difference between the effects of ethanol and saccharin solutions, but was attributable to methodological differences between the alcohol and saccharin studies. In the alcohol studies, alcohol was continuously available during the periods of access; whereas, in the saccharin studies, the sodium saccharin solution was typically presented for only $1 \mathrm{~h} /$ day.

Thus, in Experiment 1 the magnitude of the saccharin elation effect produced following the cessation of a $1-\mathrm{h} /$ day regimen of access was compared with that produced by withdrawal following continuous access. The hypothesis was that the effect would be more striking in the latter condition. This comparison was made at two different saccharin concentrations because the generality of the saccharin elation effect across different concentrations had yet to be established.

\section{Method}

Serving as subjects were 60 naive male black-hooded rats $(400-500 \mathrm{~g})$ purchased from the Canadian Breeding Farm and Laboratories (LaPrairie, Quebec). Each rat was housed individually with Purina $\mathrm{Lab}$ Chow and water available at all times. The rats were weighed once a week but otherwise remained unhandled.

Sodium saccharin was prepared in $.15 \%$ and $1.5 \%$ solutions (weight/volume in tap water) and stored at room temperature in closed, polyethylene containers for at least $24 \mathrm{~h}$ before presentation. Water was stored prior to presentation in the same fashion for an equal period of time. The fluids were presented to the animals in 250-ml bottles fitted with stainless steel drinking spouts. The ball-tipped spouts (Atco Manufacturing Company, Napa, California), which minimized drippage and evaporation, were introduced through the front of the cage at one of two positions, left or right.

The rats were divided into four groups of 15 on the basis of body weight. Each rat had continuous access to water for the 38 days of the experiment and access to one of the saccharin solutions on each day of the experiment except Days 31 to 34 inclusive. Animals in two of the groups had continuous access to either the $.15 \%(.15 \%$-continuous group) or the $1.5 \%(1.5 \%$ continuous group) saccharin solutions on the days when saccharin was available. On the same days, animals in each of the 
remaining two groups received access to either the $.15 \%$ (.15\%-h group) or the $1.5 \%(1.5 \%$-h group) solution for $1 \mathrm{~h} / \mathrm{day}$. Thus, the design was a 2 by 2 factorial, with the two variables being saccharin concentration and the schedule of saccharin availability.

Each morning $200 \mathrm{ml}$ of water and an equal amount of one of the sodium saccharin solutions, if required, were presented to each animal. The saccharin solutions were removed $1 \mathrm{~h}$ later from the cages of the subjects in the "hour groups" and the volume of solution consumed was determined by subtraction. The next morning the water bottles of all the subjects and the saccharin solutions of subjects in the "continuous groups" were removed, and the volume of consumption was assessed before fresh quantities of saccharin solution and water were presented. Each day the position of the bottle, or bottles, was randomly determined to eliminate any confounding effects of position preference. However, no animals developed an obvious position preference during the course of the experiment.

\section{Results and Discussion}

The major results of the experiment are presented in Figure 1. On the day after the period of nonaccess (Day 35 ), the saccharin consumption of both the .15\%continuous (sign test, $\mathrm{n}=15, \mathrm{X}=15, \mathrm{p}<.0001$ ) and the $1.5 \%$-continuous (sign test, $\mathrm{n}=13, \mathrm{X}=12, \mathrm{p}<.001$ ) groups was approximately twice as great as on the last baseline day (Day 30), while the period of nonaccess had no significant effect $(p>.05)$ on saccharin consumption in either of the "hour groups."

Thus, the major hypothesis was confirmed: The magnitude of the saccharin elation effect depended on the schedule of saccharin presentation during the baseline period. In the present experiment no significant effect was observed when the usual $1-\mathrm{h} /$ day exposure

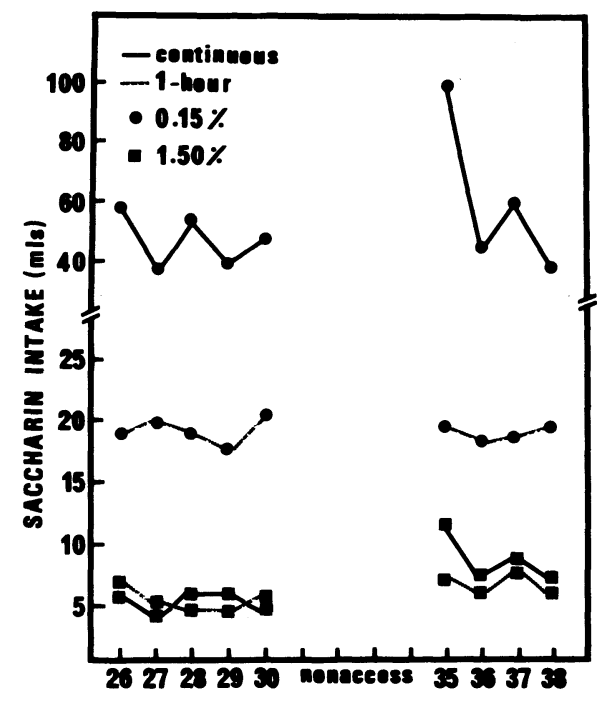

Dars

Figure 1. Daily consumption of saccharin solutions before and after a temporary period of nonaccess. Rats were exposed to $.15 \%$ or $1.5 \%$ solutions continuously or for $1 \mathrm{~h} / \mathrm{day}$ in the pre- and post-withdrawal periods. period was used, but in the continuous condition the effect of a period of nonaccess produced a striking, but temporary, increase in saccharin selection. This effect was observed at both preferred (.15\%) and nonpreferred (1.5\%) concentrations, thus establishing its generality.

The present results are consistent with those of the one study in the literature which did not use the usual 1-h/day saccharin-exposure schedule. Hoyenga and Hoyenga (1973) provided animals with continuous access to sodium saccharin solutions during the baseline period, and marked increases in saccharin selection were observed after each of three different periods of nonaccess. However, it was not clear in their study whether the marked increases in saccharin solutions were attributable to the continuous access or to some other feature of their methodology.

Variation in the saccharin concentration had the marked effect on consumption predictable on the basis of previous investigations (cf. Hammer, 1967). In the continuous condition the average daily consumption of the $.15 \%$ and the $1.5 \%$ solutions was 50 and $7 \mathrm{ml}$, respectively, and 20 and $7 \mathrm{ml}$ were the respective figures for the hour condition. The palatability of the $.15 \%$ solution was also indicated by the minimal consumption of water $(6 \mathrm{ml} / \mathrm{day})$ on the part of the animals in the .15\%-continuous group. The animals in each of the other three groups consumed about $35 \mathrm{ml}$ of water daily. It should be emphasized that, although concentration had a marked effect on the volume of the solution consumed, saccharin elation effects were produced at both concentrations in the continuous condition.

\section{EXPERIMENT 2}

The relation between the duration of the period of nonaccess and the magnitude of the saccharin elation effect has been a question of major interest in this field. However, as Hoyenga and Hoyenga (1973) have previously pointed out, the results of investigations into this question have been far from systematic. In two studies (Ashton, Gandelman, \& Trowill, 1970; Gandelman \& Trowill, 1969), the saccharin elation effect was demonstrated with a 3-day withdrawal interval, whereas Dube, Ashton, and Trowill (1970) found a significant effect with a 1-day, but not a 3-day, interval. Di Lollo and Meyer found no effect with either a 5-day (Di Lollo \& Meyer, 1970a) or 6-day (Di Lollo \& Meyer, 1970b) withdrawal period.

The inconsistent nature of these results may have been largely attributable to the fact that withdrawal following a 1-h/day exposure schedule does not reliably produce the saccharin elation effect; in Experiment 1 a significant saccharin elation effect was not produced at either of two saccharin concentrations with this standard exposure schedule. Thus, in Experiment 2, the relation between the duration of the period of 
nonexposure and the magnitude of the saccharin elation effect was examined using the more reliable continuousexposure schedule.

\section{Method}

The method was similar to that used in Experiment 1 except for the following differences. All 60 experimentally naive rats received continuous access to water for the 18 days of the experiment and to a $.15 \%$ saccharin solution for the first 7 days of the experiment, at which point they were divided into four equal groups $(n=15)$ on the basis of their total consumption of saccharin on Day 7. The control group was maintained on this same schedule of continuous saccharin exposure until the end of the experiment, whereas, beginning on Day 8 , the three experimental groups had their access to the saccharin solutions interrupted for 1,3 , or 5 days.

\section{Results}

From Figure 2 it is apparent that the magnitude of the saccharin elation effect was an increasing function of the duration of the period of nonaccess. On the first day following the period of nonaccess, animals in the 1-day (sign test, $\mathrm{n}=15, \mathrm{X}=11, \mathrm{p}<.05$ ), 3-day (sign test, $\mathrm{n}=14, \mathrm{X}=13, \mathrm{p}<.001$ ), and 5 -day (sign test, $\mathrm{n}=15, \mathrm{X}=15, \mathrm{p}<.0001)$ groups consumed significantly greater volumes of the saccharin solution than they had on Day 7 , the day prior to the withdrawal period. The significance of this effect was also confirmed by between-subjects comparisons. In the first day following the period of nonaccess, subjects in the 5-day $\left(\mathrm{U}=8, \mathrm{~N}_{1} / \mathrm{N}_{2}=15 / 15, \mathrm{p}<.0001\right)$ and 3-day $\left(\mathrm{U}=47, \mathrm{~N}_{1} / \mathrm{N}_{2}=15 / 15, \mathrm{p}<.01\right)$ groups, but not those in the 1-day group $\left(U=108, N_{1} / N_{2}=15 / 15\right.$, $p>.05)$ consumed significantly more than did the control animals on the same day. Also apparent in Figure 2 is the initial acclimation to saccharin (cf. Di Lollo \& Meyer, 1970a, b; Pinel \& Huang, 1976). Over the first 7 days of the experiment there was a sig-

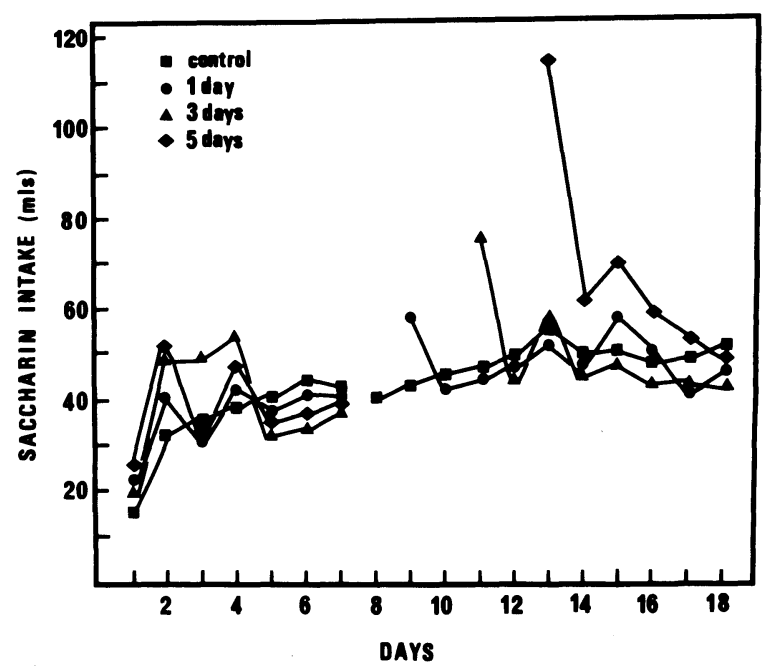

Figure 2. Duration of nonaccess and the magnitude of the saccharin elation effect. nificant increase in saccharin consumption (sign test, Day 1 vs Day $7, \mathrm{n}=60, \mathrm{X}=51, \mathrm{p}<.001$ ).

It should be noted that the group with the 5-day rest interval in this experiment was tested under conditions similar to those of the .15\%-continuous group in Experiment 1 . The performance of these two groups in their respective experiments was almost identical (compare Figures 1 and 2), thus illustrating again the reliability of the saccharin elation effect under the conditions employed in these experiments.

\section{DISCUSSION}

The similarity of the results of the present experiments with those of previous studies of the alcohol deprivation effect reinforces the notion that the elevation in the selection of weak saccharin and ethanol solutions following a temporary period of withdrawal is controlled by a single underlying mechanism. Sinclair (1972) found that a marked alcohol deprivation effect could be produced under a wide variety of experimental conditions; however, temporary withdrawal from a schedule under which alcohol was available for only $1 \mathrm{~h} /$ day produced only a slight increase in alcohol selection. Sinclair, Walker, and Jordan (1973) subjected rats to alcohol deprivation periods ranging from 90 min to 75 days. As in Experiment 2, the magnitude of the resulting change in selection was a monotonically increasing function of the duration of the withdrawal period.

The results of studies which have examined the increase in the selection of particular sapid solutions produced by single or multiple periods of withdrawal have recently been organized under a single conceptual framework (Pinel \& Huang, 1976) based on the work of Holman (1973). Holman found that the consumption of a sapid solution for just $30 \mathrm{~min}$ would inhibit a rat's subsequent selection of that solution in a choice situation. Since this inhibitory effect was demonstrable with a variety of sapid solutions, taste alone seems to have been the critical factor. Thus, the continued experience of a particular taste seems to produce an inhibition which tends to decrease the selection of that taste in subsequent choice situations. Pinel and Huang (1976) have suggested that the magnitude of this inhibitory effect might increase with continued exposure to a particular taste and gradually diminish over periods of nonexposure, thus accounting for the increase in selection following a period of withdrawal.

\section{REFERENCES}

Ashton, A., Gandelman, R. J., \& Trowill, J. A. Effect of food deprivation upon elation of saccharin drinking following a temporary shift to water. Psychonomic Science, 1970, 21, 5-6.

Di Lollo, V., \& MeYer, P. N. Variations in fluid intake following shifts between water and saccharin solution. Psychonomic Science, 1970, 18, 55-56. (a)

Di Lollo, V., \& MeYer, P. N. Pattern of daily water consumption in relation to intake of saccharin solution. Psychonomic Science, 1970, 20, 265-266. (b)

Dube, R., Ashton, A. B., \& Trowill, J. A. Responses of palatability shifts: Effects of varying the retention level. Psychonomic Science, 1970, 21, 10-12.

Gandelman, R., \& Trowill, J. A. Effects of reinforcement shifts upon subsequent saccharin consumption. Psychonomic Science, 1969, 15, 25.

HAMmER, L. R. Saccharin and sucrose intake in rats: Longand short-term tests. Psychonomic Science, 1967, 8, 367-368.

Holman, E. W. Temporal properties of gustatory spontaneous 
alternation in rats. Journal of Comparative and Physiological Psychology, 1973, 85, 536-538.

Hoyenga, K. T., \& Hoyenga, K. B. Experimental factors in the enhancement of saccharin intake after shifts to water. Animal Learning \& Behavior, 1973, 1, 244-246.

Pinel, J. P. J., \& HuAng, E. Effects of periodic withdrawal of ethanol and saccharin selection in rats. Physiology and Behavior, 1976, 16, 643-698.

Sinclair, J. D. The alcohol-deprivation effect: Influence of various factors. Quarterly Journal of Studies on Alcohol, 1972, 33, 769-782.
Sinclair, J. D., Walker, S., \& Jordan, W. Behavioral and physiological changes associated with various durations of alcohol deprivation in rats. Quarterly Journal of Studies on Alcohol, 1973, 34, 744-757.

WAYNer, M. J., Greenberg, I., TARTAglione, D., Nolley, D., Fraley, S., \& Cott, A. A new factor affecting the consumption of ethyl alcohol and other sapid fluids. Physiology and Behavior, 1972, 8, 345-362.

(Received for publication November 19, 1976.) 